\title{
THE EFFECT OF CLIMATIC PARAMETERS AND SEASONAL VARIATION ON AREA PREFERENCES OF DAIRY GOATS IN CONVENTIONAL LOOSE HOUSING WITH OUTSIDE ENCLOSURE
}

\author{
Selda Uzal Seyfi ${ }^{*}$ \\ ${ }^{1}$ Department of Farm Structures and Irrigation, Agricultural Faculty, Selçuk University, Konya 42079, Turkey; \\ *Corresponding Author Selda Uzal Seyfi, E-mail: seldauzal@selcuk.edu.tr;
}

Received December 2018; Accepted Jaunary 2019; Published February 2019;

DOI: https://doi.org/10.31407/ijees9124

UOI license: http://u-o-i.org/1.01/ijees/50760560

\begin{abstract}
Barn design taking into account barn area preferences and welfare of animals plays an important role for goat milk production. Although area preferences and behaviour indices were studied for cattle, behaviour indices for goats is unavailable. The aim of this study was to defined, as a novelty in the literature, goat behaviour indices and to investigate the hourly and seasonal changes in the barn area preferences of Saanen dairy goats and seasonal variation of defined behaviour indices of the goats (207 animals) in conventional housing with outside enclosure. Animals were monitored using continuous video record ( $24 \mathrm{~h}$ per d) in the housing during a year. By using a 60 -min scan sampling technique, the animals were videotaped for a total of $30 \mathrm{~d}(720 \mathrm{~h})$ in summer, autumn and winter. The design of the study contained the hourly and seasonal variation of four different barn area preferences (resting, courtyard, feeding and watering area). Temperatures, relative humidity and temperature and humidity index (THI) were evaluated at five-minute intervals. As new goat behaviour indices, the values of the goat comfort index (GCI), the eligible goat comfort index (EGCI), the goat stress index (GSI), and resting area usage index (RUI) was defined and calculated. A factorial experimental design was used to analyse all behavioural data. The dairy goats preferred using the courtyard (open area) at a higher rate (73.3, and 65.7\%) to the resting area (closed area) for resting and standing except for winter $(\mathrm{P}<0.01)$. GCI for summer, autumn and winter were $0.003,0.030$, and 0.636 whereas GSI for same seasons were $0.137,0.125$, and 0.127 , respectively $(\mathrm{P}<0.01)$. Development of alternative new barn design taking into account area preferences and behaviour indices instead of conventional housing is important to increase milk production and welfare of goat.
\end{abstract}

Keywords: goat behaviour, goat housing, goat behaviour indices, barn area preference, conventional housing. 